\title{
Development and validation of weather based prediction model for Helicoverpa armigera in chickpea
}

\author{
D. SAGAR*, SURESH M. NEBAPURE and SUBHASH CHANDER \\ Division of Entomology, ICAR-Indian Agricultural Research Institute, New Delhi \\ *e-mail of corresponding author: garuda344@gmail.com
}

\begin{abstract}
Weather based prediction model for Helicoverpa armigera was developed and validated using pheromone trap catches data collected in chickpea crop sown on three different dates during 2015-16 and validated for 2016-17. The first catch of male moth of $H$. armigera was recorded during $1^{\text {st }}$ standard meteorological week (SMW) in early sown crop, while in normal and late sown the first trap catches were noticed during $3^{\text {rd }}$ and $5^{\text {th }}$ SMW respectively. $H$. armigera adult trap catches then increased gradually and reached their peaks simultaneously during $12^{\text {th }} \mathrm{SMW}$ with $32.3,37.3$ and $44.3 \mathrm{moths} /$ trap/week in early, normal and late sown chickpea crop respectively. Male moth population had highest significant positive correlation with maximum and minimum temperature of 2-lag week in early and normal sowing of chickpea. Morning relative humidity and evening relative humidity of current, 1-lag and 2-lag week were negatively correlated with trap catches. The rainfall of 1-lag week and sunshine hours of current week exhibited maximum positive association with male moth population. Weather based prediction models were developed for male trap catches of crop under normal date of sowing and weather factors of current, 1-lag and 2-lag week. By stepwise regression, $\mathrm{Tmin}_{\mathrm{R}} \mathrm{RH}_{1}$ and $\mathrm{SSH}$ were found to be important weather factors that influenced the trap catches of $\mathrm{H}$. armigera. The pest-weather model was validated satisfactorily with $\mathrm{R}^{2}=0.751, \mathrm{RMSE}=2.13 \%, \mathrm{MBE}=-1.08 \%$ and $\mathrm{MAE}=1.51 \%$.
\end{abstract}

Key words : Helicoverpa armigera, pheromone trap catches, weather parameters, prediction model, validation

Chickpea (Cicer arietinum L.) is the second most important pulse crop, known as king of pulses, grown globally on an area of about 14 million ha across 55 countries. India is the largest producer of chickpea with a share of 70 per cent in area and 67 per cent in production in the world (Anon., 2016).

Insect pests are the major bottlenecks in realizing the potential yield of the chickpea crop and the most important among them is the chickpea pod borer, Helicoverpa armigera (Hubner). H. armigera causes economic loss in chickpea by damaging tender foliage, flowers and pods and under favourable conditions the pod damage reaches up to 90-95 per cent (Shengal and Ujagir, 1990). Pheromone traps are the important component in integrated pest management programme for monitoring pest population, facilitating judicious pesticide application at economic threshold level of insect pests. Recent climatic changes have influenced the density of $H$. armigera population in different pulse crops (Srivastava, 2009). Weather factors such as temperature, rainfall and relative humidity greatly influence the insect pest population (Siswanto et al., 2008). The H. armigera population peaks corresponded to the full bloom and pod formation stage of chickpea (Deka et al., 1987) and favourable weather factors viz., temperature, humidity and rainfall (Yadav et al., 1991; Tripathi and Sharma, 1985). Understanding the pest-weather relationship is of paramount importance for effective pest suppression (Das et al., 2008). Pest population level may be resultant of weather parameters of preceding weeks or months. It thus becomes important to explore relationship of pest population with pre-season and seasonal weather parameters (Prasannakumar and Chander, 2014). In this context, the present investigation was carried out to develop and validate weather based prediction model for H.armigera in chickpea based on pheromone trap catch data collected in three different dates of sowing (early, normal and late sown chickpea crop) at experimental farm of ICAR-Indian Agricultural Research Institute (IARI), New Delhi.

\section{MATERIALS AND METHODS}

The experiment was conducted in the chickpea fields of ICAR- Indian Agricultural Research Institute, New Delhi $\left(28.08^{\circ} \mathrm{N}, 77.12^{\circ} \mathrm{E}, 228.61 \mathrm{~m}\right)$ during $2015-16$ and 2016 17. The chickpea was sown on three different dates of sowing viz., early crop sown during $44^{\text {th }}$ SMW, normal crop sown during $47^{\text {th }}$ SMW and late crop sown during $50^{\text {th }}$ 
Table 1: Pheromone trap catches in chickpea sown on three different dates of sowing during 2015-16

\begin{tabular}{lllll}
\hline Standard & Period & \multicolumn{3}{c}{ Average number of male moths/trap/week } \\
Meteorological Week & & Early sown crop & Normal sown crop & Late sown crop \\
\hline 51 & Dec 17- Dec 24 & $0.0(0.707)$ & $0.0(0.707)$ & $0.0(0.707)$ \\
52 & Dec 25- Dec 31 & $0.0(0.707)$ & $0.0(0.707)$ & $0.0(0.707)$ \\
1 & Jan 1- Jan 7 & $0.33(0.911)$ & $0.0(0.707)$ & $0.0(0.707)$ \\
2 & Jan 8- Jan 14 & $1.0(1.22)$ & $0.0(0.707)$ & $0.0(0.707)$ \\
3 & Jan 15-Jan 21 & $0.66(1.07)$ & $0.66(1.07)$ & $0.0(0.707)$ \\
4 & Jan 22-Jan 28 & $1.66(1.46)$ & $1.33(1.35)$ & $0.0(0.707)$ \\
5 & Jan 29- Feb 4 & $1.0(1.22)$ & $2.0(1.58)$ & $2.66(1.77)$ \\
6 & Feb 5-Feb 11 & $1.66(1.46)$ & $1.66(1.47)$ & $3.66(2.03)$ \\
7 & Feb 12 - Feb 18 & $2.33(1.68)$ & $1.66(1.47)$ & $5.0(2.34)$ \\
8 & Feb 19-Feb 25 & $3.33(1.95)$ & $2.33(1.68)$ & $4.66(2.27)$ \\
9 & Feb 26- Mar 3 & $3.0(1.87)$ & $1.33(1.35)$ & $13.0(3.67)$ \\
10 & Mar 4 - Mar 10 & $7.60(2.84)$ & $11.33(3.43)$ & $10.66(3.34)$ \\
11 & Mar 11- Mar 17 & $31.66(5.67)$ & $22.0(4.74)$ & $41.33(6.46)$ \\
12 & Mar 18- Mar 24 & $32.33(5.72)$ & $37.33(6.15)$ & $44.33(6.69)$ \\
13 & Mar 25 - Mar 31 & $21.66(4.70)$ & $30.33(5.55)$ & $20.66(4.60)$ \\
14 & Apr 1 - Apr 7 & $19.33(4.45)$ & $21.66(4.70)$ & $15.0(3.93)$ \\
15 & Apr 8 -Apr 14 & $11.66(3.48)$ & $14.33(3.85)$ & $9.33(3.13)$ \\
16 & Apr 15 - Apr 21 & $12.0(3.53)$ & $9.0(3.08)$ & $4.33(2.19)$ \\
17 & Apr 22 - Apr 28 & Harvesting was done & & \\
\hline
\end{tabular}

Figures in the parentheses are " $(\mathrm{x}+0.5)$ transformed values

SMW.All the recommended agronomic practices were followed in raising the crop. For monitoring of Helicoverpa armigera, pheromone traps procured from Pest Control India (PCI) Pvt. Ltd., were used. The pheromone traps were installed in each block on poles at $1.2 \mathrm{~m}$ height above the ground level@ 5 ha $^{-1}$. Pheromone trap lures were replaced with new ones after every 20 days. The data on adult trap catches of $H$. armigera were recorded on weekly intervals, expressed as mean number of male moths/trap/week and square root transformed before using in weather based model development. Weather data were obtained from the Agricultural Physics Division, ICAR-IARI, New Delhi. The relationship between male moth catches and weather parameters viz., maximum temperature (Tmax), minimum temperature (Tmin), morning relative humidity $\left(\mathrm{RH}_{1}\right)$, evening relative humidity $\left(\mathrm{RH}_{2}\right)$, rainfall, sunshine hours and wind speed was computed using simple correlation coefficient with the weather parameters of current week, 1-lag and 2-lag weeks. Multiple linear pest weather model was then developed between weather parameters of current week, 1-lag and 2-lag week and trap catches of crop under normal date of sowing, as normal date of sowing is routinely practiced by famers. Stepwise regression was carried out to find out the relative importance of different weather factors that in fluenced H.armigera trap catches. Model performance was evaluated by comparing the observed trap catch data of 2016-17 with predicted trap catches.Model accuracy was evaluated by comparing the root mean-square error (RMSE), mean bias error (MBE) and mean absolute error (MAE) of the predicted and observed data sets of trap catches using the following formula

Root Mean Square Error $=\sqrt{\frac{\sum_{1}^{n}(M-O)^{2}}{n}}$

Mean Bias Error $=\frac{1}{n} \sum_{1}^{n}(M-O)$ 
Mean Absolute Error $=\frac{1}{n} \sum_{1}^{n}|M-O|$

Where, $\mathrm{M}=$ predicted data, $\mathrm{O}=$ observed data, $\mathrm{n}=$ number of observations

\section{RESULTS AND DISCUSSION}

\section{Activity of Helicoverpa armigera male moths}

The pheromone trap catch data revealed the activity of male moths during January to April in all the three dates of sowing (Table 1). The first catch of male moth of $H$. armigera was recorded during $1^{\text {st }}$ SMW (Jan 1 - Jan 7) in early sown crop, while in normal and late sown the trap catches were noticed during $3^{\text {rd }}(\operatorname{Jan} 15-$ Jan 21$)$ and $5^{\text {th }}$ SMW (Jan 29- Feb 4), respectively. The differences in the male moth catch occurrence could be due to the phenology of the crop and fluctuations in the weather parameters. H. armigera adult trap catches subsequently increased gradually and reached their peaks simultaneously during $12^{\text {th }}$ SMW with 32.3, 37.3 and 44.3 moths/trap/week in early, normal and late sown chickpea crop, respectively. Earlier, Shah and Shahzad (2005) observed low population of $H$. armigera during $49^{\text {th }}$ to $6^{\text {th }}$ SMW in Faisalabad, Pakistan but population increased from $7^{\text {th }}$ SMWand then declined during $14^{\text {th }}$ SMW. Ramesh Babu et al., (2009) observed the maximum trap catches in Banswara, Rajasthan during $8^{\text {th }}$ and $9^{\text {th }}$ SMW during 2007-08 and 2008-09. Likewise, Mahapatra et al., (2007) observed higher number of trapped moths during March and April months in Uttarakhand hills.

\section{Correlation studies}

Amongst current, 1-lag and 2-lag week weather parameters, the male moth population had highest significant positive correlation with Tmax and Tmin of 2-lag week in early and normal date of sowing (Table 2). The $\mathrm{RH}_{1}$ and $\mathrm{RH}_{2}$ were negatively correlated with trap catches in current, 1lag as well as 2-lag week. However significant correlation of moth catches was observed with current week weather data in early sowing. Ramesh Babu et al. (2009) observed Tmax and $\mathrm{RH}_{2}$ of Banswara, Rajasthan had significant positive and negative correlation respectively with male moth catches during 2008-09 which corroborates present findings. Vaishampayan (1980) observed non-significant negative correlation between temperature and trap catches that contradicted present findings. In present study, sunshine hours of current week had highest positive association with the population of $H$. armigera male moths in early and normal sowing. In all three dates of sowing, the rainfall of 1- 
Table 3: Regression analysis between pheromone trap catches of $H$. armigera and weather parameters in normal date of sowing

\begin{tabular}{lllll}
\hline $\begin{array}{l}\text { Date of } \\
\text { sowing }\end{array}$ & Week & Regression equation & $\mathrm{R}^{2}$ & $\begin{array}{l}\text { Equation } \\
\text { number }\end{array}$ \\
\hline Normal & Current & $\mathrm{Y}=-22.85+0.379 \mathrm{x}_{1}-0.256 \mathrm{x}_{2}+0.049 \mathrm{x}_{3}+0.171 \mathrm{x}_{4}+0.346 \mathrm{x}_{5}+0.30 \mathrm{x}_{6}+0.519 \mathrm{x}_{7}$ & 0.779 & 1 \\
$(\mathrm{~N}=14)$ & $1 \mathrm{Lag}$ & $\mathrm{Y}=-9.74-1.156 \mathrm{x}_{1}+1.66 \mathrm{x}_{2}+0.093 \mathrm{x}_{3}+0.258 \mathrm{x}_{4}+2.14 \mathrm{x}_{5}-0.857 \mathrm{x}_{6}-1.75 \mathrm{x}_{7}$ & 0.824 & 2 \\
& $2 \mathrm{Lag}$ & $\mathrm{Y}=-10.69-0.685 \mathrm{x}_{1}+1.21 \mathrm{x}_{2}+0.177 \mathrm{x}_{3}+0.038 \mathrm{x}_{4}+1.11 \mathrm{x}_{5}-0.25 \mathrm{x}_{6}-0.99 \mathrm{x}_{7}$ & 0.85 & 3 \\
\hline
\end{tabular}

$\mathrm{X}_{1}=$ maximum temperature $\left({ }^{\circ} \mathrm{C}\right), \mathrm{X}_{2}=$ minimum temperature $\left({ }^{\circ} \mathrm{C}\right), \mathrm{X}_{3}=$ morning relative humidity $(\%), \mathrm{X}_{4}=$ evening relative humidity $(\%), X_{5}=$ sunshine hours, $X_{6}=\operatorname{rainfall}(\mathrm{mm}), X_{7}=$ wind speed $(\mathrm{kmph})$

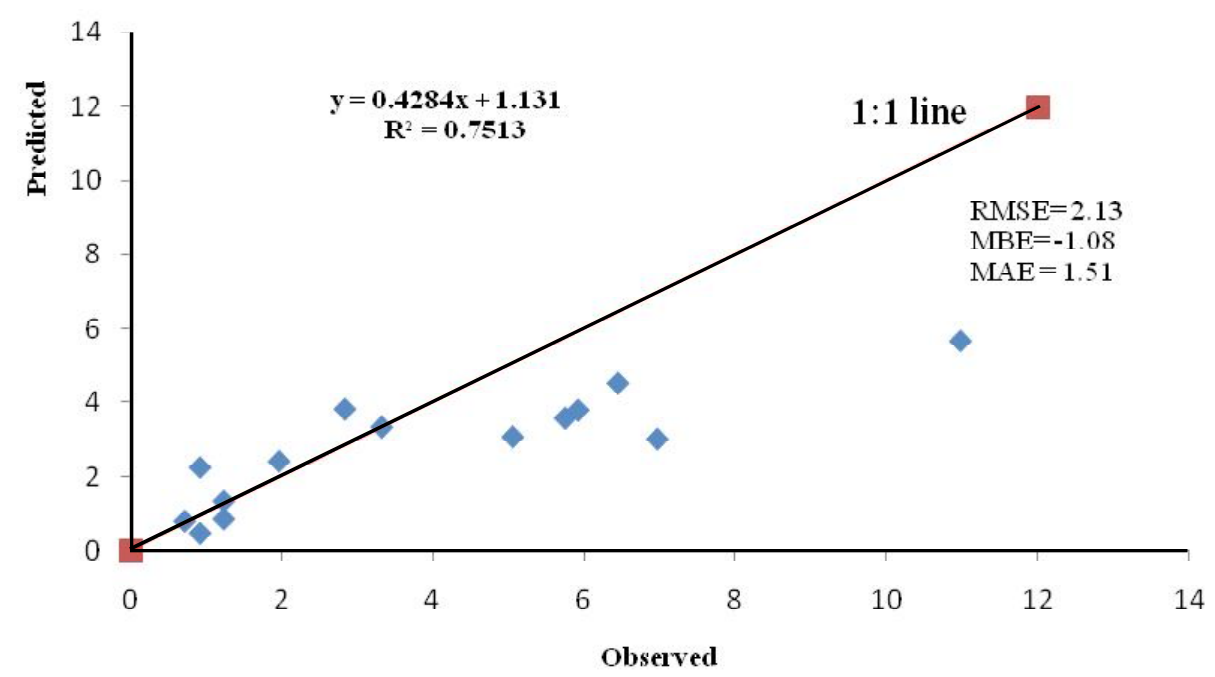

Fig. 1: Observed and predicted trap catches of Helicoverpa armigera under normal sowing during (2016-17)

lag week exhibited maximum positive association with male moth population, while the wind speed of current week showed highest positive association. Earlier, Jayaramiah and Babu (1990) reported the rainfall to be an influencing factor for H. armigera moth emergence, while Ramesh Babu et al. (2009) observed that sunshine hours had positive correlation and wind speed had negative association with adult trap catches of $H$. armigera. In Banswara, Rajasthan the diurnal variations with respect to temperature during rabi season has been observed to be highest as compared to our study area. The variation in weather factors across different locations was thus probably responsible for differences in moth multiplication of $H$. armigera.

\section{Model development}

As the normal sowing of chickpea is the practice predominately followed by the farmers, so weather based regression model was thus developed only in respect of normal sowing by taking male moth catches of $H$. armigera (y) as a dependent variable and weather parameters of current, 1-lag and 2-lag weeks (x) as independent variable (Table 3).
From the regression equation (1) it could be deduced that for every $1{ }^{\circ} \mathrm{C}$ increase in Tmax the male moth catches of $H$. armigera increased by 0.379 per trap per week, while decrease in Tmin by $1^{\circ} \mathrm{C}$ increased the trap catches by 0.256 per trap per week. Likewise, decrease in $1 \mathrm{~mm}$ of rainfall decreased trap catch by 0.30 per trap per week. The coefficient of determination $\left(\mathrm{R}^{2}=0.779\right)$ indicated that 77.9 per cent variability in male moth catches of $H$. armigera was accounted by different weather factors. Earlier Ramesh Babu et al. (2009) reported that 88.08 per cent variations in male moth catches of $H$. armigera in chickpea crop due to various weather factors during 2007-08 in Banswara, Rajasthan.

Among the three models developed in (Table 3) respect of normal sowing, the coefficient of determination $\left(\mathrm{R}^{2}=0.85\right)$ was highest in regression equation 3 , so it was considered for stepwise regression to find out the significant weather factor influencing male moth catches of $H$. armigera.

Hence the final model with $\mathrm{Tmin}, \mathrm{RH}_{1}$ and $\mathrm{SSH}$ was established as

$\mathrm{Y}=-21.15+0.409 * \mathrm{Tmin}+0.202 * \mathrm{RH}_{1}+0.346 * \mathrm{SSH} \quad\left(\mathrm{R}^{2}=0.792\right)$ 
By stepwise regression, Tmin, $\mathrm{RH}_{1}$ and $\mathrm{SSH}$ were found to be important factors that influenced the trap catches of $H$. armigera.

\section{Model validation}

The final model was validated by comparing the observed trap catch data of crop season 2016-17 with predicted trap catches. The pest-weather model was validated satisfactorily $\left(\mathrm{R}^{2}=0.7513, \mathrm{RMSE}=2.13 \%, \mathrm{MBE}=-\right.$ $1.08 \%$ and $\mathrm{MAE}=1.51 \%$ ) (Fig. 1). Pest weather model clearly suggested $\mathrm{Tmin}, \mathrm{RH}_{1}$ and $\mathrm{SSH}$ to be the important weather parameters that influenced the trap catches of $H$. armigera under New Delhi environment. Besides, satisfactory validation, the model also endorsed the importance of these three important weather parameters in affecting $H$. armigera population dynamics. It has also been observed earlier that although empirical pest-weather models had contributed significantly in understanding pest population dynamics but these were influenced by local conditions and thus behaved in a location-specific manner (Pinnschmidet et al., 1995; Teng. et al., 1998).

\section{CONCLUSION}

The effect of weather parameters on $H$. armigera moth catches in present study thus differed somewhat from earlier studies. The developed models can be used for predicting $H$. armigera moth catches, which would indirectly serve as an indicator of field incidence of pest.

\section{ACKNOWLEDGEMENTS}

With at most pleasure and sincerity, the authors thankfully acknowledge whole heartedly Dr. C. Bharadwaj, Dr. Venkatraman Hegde and Dr. Shailesh Tripathi of Genetics Division, ICAR-IARI, New Delhi for their help to undertake this study.

\section{REFERENCES}

Anonymous, (2016). Project Co-ordinators report2015-16. All Indian Co-ordinated Research project on chickpea, ICAR-Indian Institute of Pulses Research. pp.1-47.

Das, D. K., Behera, K. S., Dhandapani, A., Trivedi, T.P., Chona, N. and Bhandari, P. (2008). Development of forewarning systems of rice pests for their management.In: "Rice Pest management” (eds. A. Prakash, A. Sasmal, J.Rao, S.N,Tewari, K.S.Behera, S.K. Singh and V. Nandagopal).pp. 187-200.

Deka, N.K., Prasad, D. and Chand, P. (1987). Succession and incidence of insect pests in chickpea, Cicer arietinum L. Giornale Italiano diEntomol., 3: 421-428.
Jayaramiah, M. and Babu, H.C.S. (1990). Present status of Helicoverpa armigera in pulse and strategies for its management in Karnataka. Proceeding First National Workshop Helicoverpa Management, Directorate of Pulse Research, Kanpur, India, 30 ${ }^{\text {th }}$ August, 1990. pp. 54-58.

Mahapatra, S. D.,Aswal, J.S. and Mishra, P.N. (2007). Monitoring population dynamics of tomato fruit borer, Helicoverpa armigera Hubner moths through pheromone traps in Uttaranchal Hills. Indian J. Entomol., 69(2): 172-173.

Pinnschmidt, H.O., Batchelor, W.D. and Teng, P.S. (1995). Simulation of multiple species pest damage on rice. Agric. Systems, 48: 193-222.

Prasannakumar, N. R. and Chander, S. (2014). Weather-based brown planthopper prediction model at Mandya, Karnataka. J. Agrometeorol.,16(1): 126-129.

Ramesh Babu, S., Rupawat, K. S. and Prashant P. Jambhulkar, (2009) Monitoring of adult populations of Helicoverpa armigera (Hubner) on chickpea using pheromone trap in southern humid zone of Rajasthan. Indian J. Appl. Entomol.,23(2): 585-589.

Shah, Z. A. and Shahzad, Md. K. (2005). Population fluctuations with reference to different developmental stages of Helicoverpa armigera (Lepidoptera : Noctuidae) on chickpea and their relationship with the environment. Int. J. Agri. Biol., 7(1):90-93.

Shengal, V. K. and Ujagir, R. (1990). Effect of synthetic pyrethroids, neem, extracts and other insecticides for the control of pod damage by Helicoverpa armigera on chickpea and pod damage-yield relationship at Patancheru in Northern India. Crop Prot., 9: 29-32.

Siswanto, Rita, M., Dzolkhifli,O. and Elna, K. (2008). Population fluctuation of Helopeltisantonii Signoret on Cashew Anacardiumoccidentalle L. in Java Indonesia. Pertanika J. Tropical Agric. Sci.,31: 191- 196.

Srivastava, C.P. (2009). Impact of climate change on insect pests of pulses and their management. In National Conference: Applied Entomology, Impact of global warming on the incidence and management of insectpests in agriculture, Entomological Research Association, MPUAT, Udaipur, Rajasthan, India. pp.3-5.

Teng, P.S., Batchelor, W.D., Pinnschmidt, H.O. and Wilkerson, G.G. (1998). Simulation of pest effects on crops using coupled pest-crop models: the potential for decision support,pp. 221-226. In:”Understanding Options for 
Agricultural production"(eds. Tsuji et al.).Kluwer Academic Press, Great Britain.

Tripathi, S. R. and Sharma, S. K.(1985). Population dynamics of Heliothis armigera (Hubner) (Lepidoptera Noctuidae) on gram in the Teraibelt of N. E. Uttar Pradesh. Giornale Italiano di Entomol., 2: 347-53.

Vaishampayan, S.M. (1980). Seasonal abundance and activity of gram pod borer moths Heliothis armigera on light trap equipped with mercury vapour lamp at Jabalpur. Indian J. Ecol., 7: 147-154.

Yadav, C.P., Lal, S.S. Ahmad, R. and Sachan, J.N. (1991). Influence of abiotic factors on relative abundance of podborers of chickpea (Cicer arietinum). Indian J. Agric. Sci., 61: 512-515. 